\title{
Analysis of Rectangular Plates Based on the Hydrostatic Point Phenomenon
}

\author{
Mohammad Alhassan, Rajai Al-Rousan, Moheldeen Hejazi \\ Jordan University of Science and Technology (JUST) \\ P.O.Box 3030, Irbid, Jordan \\ maalhassan@just.edu.jo; rzalrousan@just.edu.jo; mahejazi16@just.edu.jo
}

\begin{abstract}
This paper provides innovative analysis of rectangular plates having various aspect ratios and boundary conditions based on a true understanding of the two-way action. Nine plates with different boundary conditions, each having 11 aspect ratios were uniquely analysed using SAP2000 software. The finite element analysis results were validated against mathematical solutions showed a satisfactory agreement. The hydrostatic point phenomenon was established as the reference point for identifying plates with actual twoway action and as the growth reference for other cases, allowing for the use growth models for both the hydrostatic and deviatoric moment tensors. The innovative selection of the extreme positive point moment facilitates the introduction of material nonlinearity into the design. The plate shorter dimension was used for moment normalization in both directions to preserve the directional influence of the dimensions and to isolate the hydrostatic phenomenon. It was found that for any boundary conditions, through starting at a hydrostatic phenomenon occurrence and via fixing a dimension and extending the perpendicular dimension, the extreme point Mohr circle develops from the hydrostatic point phenomenon as a growth in the hydrostatic component and a more radical growth in the deviatoric component. The largest principal moment develops a higher magnitude as the aspect ratio increases. The presence of non-identical boundary conditions in the plate on two perpendicular directions results in a deviation of the two-way action.
\end{abstract}

Keywords: Rectangular Plates, Hydrostatic Point Phenomenon, Mohr Circle; Deviatoric Component.

\section{Introduction}

The meditative investigations into the out-of-plane loaded elements such as beams and plates followed different streams in approaching the broad range of problems, and thus, establishing different perceptions, formulations and practices [1-3]. It was in observing the natural behaviour of a cantilever beam [4], when Galileo commenced the contributions toward understanding the flexural responses [1]. Yet, it was in the eighteenth century when the solid mathematical formulations started to emerge with Euler [5-7] and Bernoulli [8], through tackling the flexural response of the out-of-plane loaded elements [9-11]. Such formulations and understanding of the flexural nature reached a climax with Germain and Lagrange $[12,13]$, Poisson and Kirchhoff [14-16] in both the Cartesian and polar coordinates [17]. Later, in eliminating that coordinates interference in understanding the laws of nature, Einstein [18] introduced the concept of general covariance based on tensor notations and formulations [19]. In order to describe the flexural behaviour of the out-of-plane loaded elements, this study introduces coordinates-independent (coordinates-free) tensor-based differential equations. The moment and curvature tensors were resolved into hydrostatic and deviatoric tensors; four-dimensional boundary value problem (4D-BVP) system visualization [20]. The behaviour of these tensors; i.e. the mean (hydrostatic) and deviatoric moment's tensors, were investigated for various boundary conditions at the extreme-positive section in the mid-span of rectangular plates having aspect ratios in the range of 0.5-1.0. Linear computational analysis using SAP2000 software package [21] was implemented. This investigation draws an insight onto the growth behaviour of continuum tensors (mean and deviatoric), and uncover the limits of such response growth.

\section{Model Synthesis}

The linear material properties in this modelling problem were chosen to be of an arbitrary linear-elastic plate having a modulus of elasticity of $25 \mathrm{GPa}$ and Poisson's ratio of 0.18 . These parameters will directly affect the flexural and hydrostatic rigidities. Nevertheless, such material parameters have no effect on the moment response in linear-elastic plates. The models to be implemented in this linear-elastic investigation were selected to be shell element with thin section definition. In 
SAP2000 software, shell elements are types of area objects used to model plates and shells in planar and 3-dimensional structural modelling. The modelling herein assumes homogeneous material properties. The planer shell element as implemented in the SAP2000 model has 4-node element formulation with linear interpolation rules combines both plates and membranes bending behaviour. Shell stiffness is implemented through a numerical 4-point integration formulation, whereas, stresses, internal moments, and forces are evaluated through Gauss integration of (2-by-2) points and extrapolated to the element joints. The difference in the approximations using different elements at a common node serves in the estimation of analysis approximate error. The difference could be in elements stresses, moments or internal forces. The analysis relies on splitting the boundary conditions into two major conditions of restraints; either clamped (C) or simply supported (S), based on which the following permutations for the support conditions can be identified:

$$
\text { Number of permutations }=2 \cdot 2 \cdot 2 \cdot 2=16
$$

This number represents the probability set of alternative cases, and due to the repetitive meaning of some of these boundaries and symmetry of this matrix, the permutations reduce to ten, as follows:

$$
\text { Permutations }=\left\{\begin{array}{llll}
\text { SSSS } & \text { SSSC } & \text { SSCS } & \text { SSCC } \\
\text { SCSS } & \text { SCSC } & \text { SCCS } & \text { SCCC } \\
\text { CSSS } & \text { CSSC } & \text { CSCS } & \text { CSCC } \\
\text { CCSS } & \text { CCSC } & \text { CCCS } & \text { CCCC }
\end{array}\right\}=\left\{\begin{array}{cccc}
\text { SSSS } & \text { SSSC } & \text { SSCS } & \text { SSCC } \\
\vdots & \text { SCSC } & \text { SCCS } & \text { SCCC } \\
\vdots & \ddots & \text { CSCS } & \text { CSCC } \\
\ldots & \ldots & \ldots & \text { CCCC }
\end{array}\right\}
$$

This can be interpreted with respect to two parameters, each of which represents the directional moment or rotation stiffness; denoted as FLR and FSR, symbolizing the fixation on long and short edges ratios, respectively:

$$
\text { Permutations }=\text { FLR }\left\{\begin{array}{ccc}
(0,0) & (0.5,0) & (1,0) \\
(0,0.5) & (0.5,0.5) & (1,0.5) \\
(0,1) & (0.5,1) & (1,1)
\end{array}\right\}
$$

This set of boundary conditions forms nine cases of continuity (Fig. 1) with their respective applicability to flat slab system.

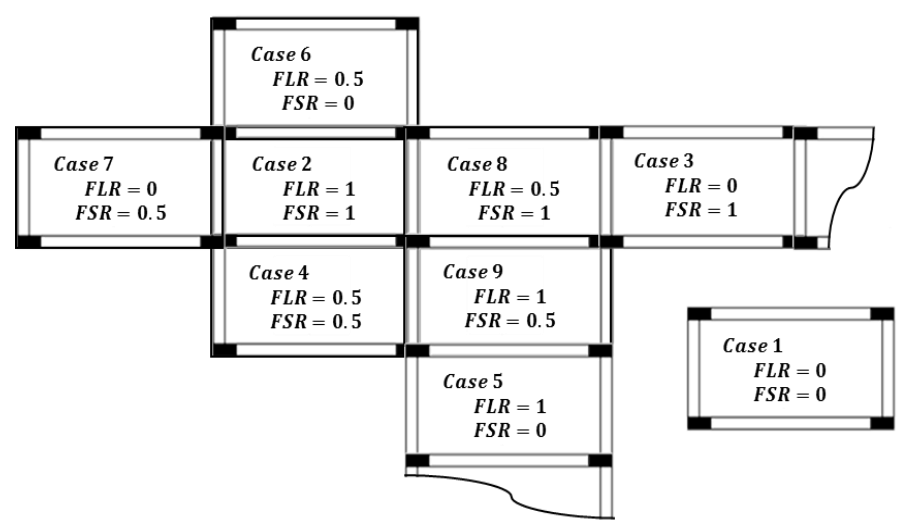

Fig. 1: Various cases of boundary conditions used in the rectangular plates analysis.

\section{Model Mathematical Validation}

Following the linear-elastic model synthesis, a validation step was necessary to assure response estimation accuracy. For this purpose, Case 1 was selected and compared with the analytical solutions of the biharmonic equations as per Navier [22-24] with the double Fourier trigonometric series, and Levy [25, 26] with the Single hyperbolic series. In the case of Navier, the solution for the moment of a simply supported homogeneous isotropic plate is given, where $\mathrm{m}$ and $\mathrm{n}$ are series indices, $\mathrm{p}$ stands for the magnitude of the applied uniformly distributed load, and $v$ symbolizes Poisson's ratio.

In estimating the moment using Eqs. 4-7, the first 100 terms were considered for the accuracy assurance. The Poisson's ratio and applied uniformly distributed load were 0.18 and 0.001 . Values obtained through these equations are listed in Table 1 and compared to values obtained by the finite element model using SAP2000 after normalization with 
the applied pressure (p) and the short span length (a). Equations estimations were carried-out using Wolfram Mathematica Computer Algebra System (CAS). Examining the results of the finite element analysis in comparison with the mathematical solutions shows a satisfactory agreement, and therefore the model was adopted.

$$
\begin{aligned}
& M_{x}=\frac{16 \cdot p}{\pi^{4}} \sum_{m=1}^{\infty} \sum_{n=1}^{\infty}\left(\frac{\left(\frac{m}{a}\right)^{2}+v \cdot\left(\frac{n}{b}\right)^{2}}{m n \cdot\left(\left(\frac{m}{a}\right)^{2}+\left(\frac{n}{b}\right)^{2}\right)^{2}} \cdot \sin \left[\frac{m \pi x}{a}\right] \cdot \sin \left[\frac{n \pi y}{b}\right]\right) \\
& M_{y}=\frac{16 \cdot p}{\pi^{4}} \sum_{m=1}^{\infty} \sum_{n=1}^{\infty}\left(\frac{v \cdot\left(\frac{m}{a}\right)^{2}+\left(\frac{n}{b}\right)^{2}}{m n \cdot\left(\left(\frac{m}{a}\right)^{2}+\left(\frac{n}{b}\right)^{2}\right)^{2}} \cdot \sin \left[\frac{m \pi x}{a}\right] \cdot \sin \left[\frac{n \pi y}{b}\right]\right)
\end{aligned}
$$

Based on Levy [25-26] solution, the expressions of bending moments for a simply supported plate is given as:

$$
\begin{aligned}
& M_{x}=\left(\frac{4 p a^{4}}{\pi^{5}}\right) \cdot \sum_{m=1}^{\infty} \frac{\sin \left[\frac{m \pi x}{a}\right]}{m^{5}}\left(( \frac { m \pi } { a } ) ^ { 2 } \cdot \left(1-\left(\frac{\alpha \cdot \operatorname{Tanh}[\alpha]+2}{2 \cdot \operatorname{Cosh}[\alpha]}\right) \cdot \operatorname{Cosh}\left[\frac{2 \alpha y}{b}\right]\right.\right. \\
& \left.+c y \cdot \sinh \left[\frac{2 \alpha y}{b}\right]\right)-v\left(\left(\frac{m \pi}{2 a \cdot \cosh [\alpha]}\right) \cdot\left(\frac{4 \alpha}{b} \cdot \cosh \left[\frac{2 \alpha y}{b}\right]+\left(\frac{2 \alpha}{b}\right)^{2} y \cdot \sinh \left[\frac{2 \alpha y}{b}\right]\right)\right. \\
& \left.\left.-\left(\frac{\alpha \cdot \operatorname{Tanh}[\alpha]+2}{2 \cdot \operatorname{Cosh}[\alpha]} \cdot\left(\frac{2 \alpha}{b}\right)^{2}\right) \cdot \cosh \left[\frac{2 \alpha y}{b}\right]\right)\right) \\
& M_{y}=\left(\frac{4 p a^{4}}{\pi^{5}}\right) \sum_{m=1}^{\infty} \frac{\sin \left[\frac{m \pi x}{a}\right]}{m^{5}}\left(v ( \frac { m * \pi } { a } ) ^ { 2 } \cdot \left(1-\left(\frac{\alpha \cdot \operatorname{Tanh}[\alpha]+2}{2 \cdot \operatorname{Cosh}[\alpha]}\right) \cdot \cosh \left[\frac{2 \alpha y}{b}\right]\right.\right. \\
& \left.+c y \cdot \operatorname{Sinh}\left[\frac{2 \alpha y}{b}\right]\right)-\left(\left(\frac{m \pi}{2 a \cdot \operatorname{Cosh}[\alpha]}\right) \cdot\left(\frac{4 \alpha}{b} \cdot \operatorname{Cosh}\left[\frac{2 \alpha y}{b}\right]+\left(\frac{2 \alpha}{b}\right)^{2} \cdot y \cdot \sinh \left[\frac{2 \alpha y}{b}\right]\right)\right. \\
& \left.\left.-\left(\frac{\alpha \cdot \operatorname{Tanh}[\alpha]+2}{2 \cdot \operatorname{Cosh}[\alpha]} \cdot\left(\frac{2 \alpha}{b}\right)^{2}\right) \cdot \cosh \left[\frac{2 \alpha y}{b}\right]\right)\right)
\end{aligned}
$$

\begin{tabular}{|c|c|c|c|c|c|}
\hline \multirow{2}{*}{\multicolumn{2}{|c|}{$\frac{\text { Short }(a)}{\operatorname{Long}(b)}$}} & \multicolumn{4}{|c|}{ Normalized Positive Moment } \\
\hline & & \multirow{2}{*}{$\begin{array}{l}\text { FEM } \\
0.044\end{array}$} & \multirow{2}{*}{\begin{tabular}{|l|} 
Navier \\
0.043 \\
\end{tabular}} & \multirow{2}{*}{\begin{tabular}{|l|} 
Levy \\
0.043 \\
\end{tabular}} & \multirow{2}{*}{$\begin{array}{l}\% \text { Error } \\
2.3\end{array}$} \\
\hline 100 & $\mathrm{Ca}_{\mathrm{a}}$ & & & & \\
\hline 1.00 & $\mathrm{C}_{\mathrm{b}}$ & 0.044 & 0.043 & 0.043 & 2.3 \\
\hline \multirow{2}{*}{0.95} & $\mathrm{C}_{\mathrm{a}}$ & 0.048 & 0.048 & 0.048 & 0 \\
\hline & $\mathrm{C}_{\mathrm{b}}$ & 0.044 & 0.044 & 0.044 & 0 \\
\hline \multirow{2}{*}{0.90} & $\mathrm{C}_{\mathrm{a}}$ & 0.051 & 0.052 & 0.052 & 1.9 \\
\hline & $\mathrm{C}_{\mathrm{b}}$ & 0.044 & 0.044 & 0.044 & 0 \\
\hline \multirow{2}{*}{0.85} & $\mathrm{Ca}_{\mathrm{a}}$ & 0.059 & 0.057 & 0.057 & 3.5 \\
\hline & $\mathrm{C}_{\mathrm{b}}$ & 0.044 & 0.044 & 0.044 & 0 \\
\hline \multirow{2}{*}{0.80} & $\mathrm{C}_{\mathrm{a}}$ & 0.062 & 0.062 & 0.062 & 0 \\
\hline & $\mathrm{C}_{\mathrm{b}}$ & 0.044 & 0.044 & 0.044 & 0 \\
\hline \multirow{2}{*}{0.75} & $\mathrm{Ca}_{\mathrm{a}}$ & 0.069 & 0.068 & 0.068 & 1.5 \\
\hline & $\mathrm{C}_{\mathrm{b}}$ & 0.043 & 0.043 & 0.043 & 0 \\
\hline \multirow{2}{*}{0.70} & $\mathrm{C}_{\mathrm{a}}$ & 0.075 & 0.074 & 0.074 & 1.4 \\
\hline & $\overline{C_{b}}$ & 0.042 & 0.042 & 0.042 & 0 \\
\hline
\end{tabular}

Table 1: Linear elastic model validation for a rectangular simply-supported plate against the analytical solutions of Navier and Levy. 


\begin{tabular}{|l|l|l|l|l|l|}
\hline \multicolumn{3}{|c|}{ Short $(a)$} & \multicolumn{4}{|c|}{ Normalized Positive Moment } \\
\cline { 2 - 6 } \multicolumn{2}{|c|}{ Long $(b)$} & FEM & Navier & Levy & $\%$ Error \\
\hline \multirow{2}{*}{0.65} & $\mathrm{C}_{\mathrm{a}}$ & 0.080 & 0.080 & 0.080 & 0 \\
\cline { 2 - 6 } & $\mathrm{C}_{\mathrm{b}}$ & 0.040 & 0.041 & 0.041 & 2.4 \\
\hline \multirow{2}{*}{0.60} & $\mathrm{C}_{\mathrm{a}}$ & 0.086 & 0.086 & 0.086 & 0 \\
\cline { 2 - 6 } & $\mathrm{C}_{\mathrm{b}}$ & 0.039 & 0.039 & 0.039 & 0 \\
\hline \multirow{2}{*}{0.55} & $\mathrm{C}_{\mathrm{a}}$ & 0.093 & 0.093 & 0.093 & 0 \\
\cline { 2 - 6 } & $\mathrm{C}_{\mathrm{b}}$ & 0.038 & 0.037 & 0.037 & 2.7 \\
\hline \multirow{2}{*}{0.50} & $\mathrm{C}_{\mathrm{a}}$ & 0.100 & 0.100 & 0.100 & 0 \\
\cline { 2 - 6 } & $\mathrm{C}_{\mathrm{b}}$ & 0.037 & 0.035 & 0.035 & 5.7 \\
\hline
\end{tabular}

Simulation using a mesh of thin plate elements of size 1/20 of least plate dimension was conducted. Fig. 2 shows the mesh on the plate with the dimensions' notation. In this model, the option "Plate-thin" element was adopted with an assigned thickness of $50 \mathrm{~mm}$ for all aspect ratios. After validation, a mesh sensitivity analysis was conducted. Firstly, a convergence study on deflection was conducted through varying mesh density (Fig. 3). Then a convergence study on the bending moments was conducted as depicted in Fig. 3 for mesh densities of 1/20 and 1/4. A mesh size of a/20 was found to achieve the optimum results and therefore it was adopted herein.

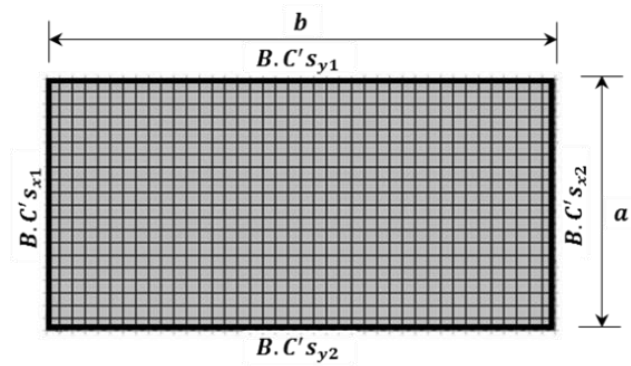

Fig. 2: The linear-elastic model using SAP2000 software.

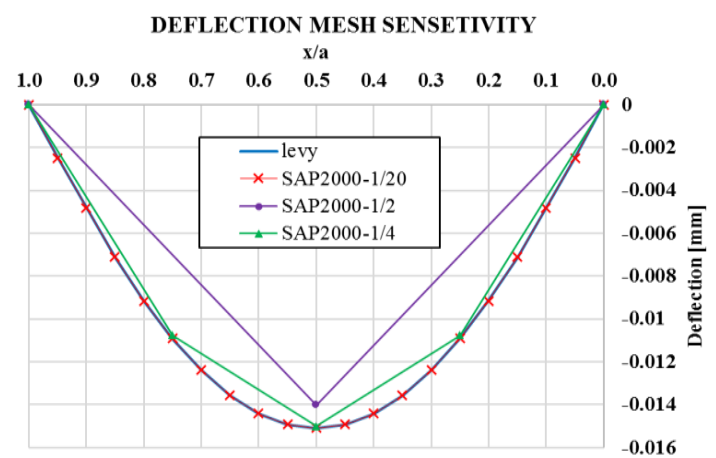

(a)

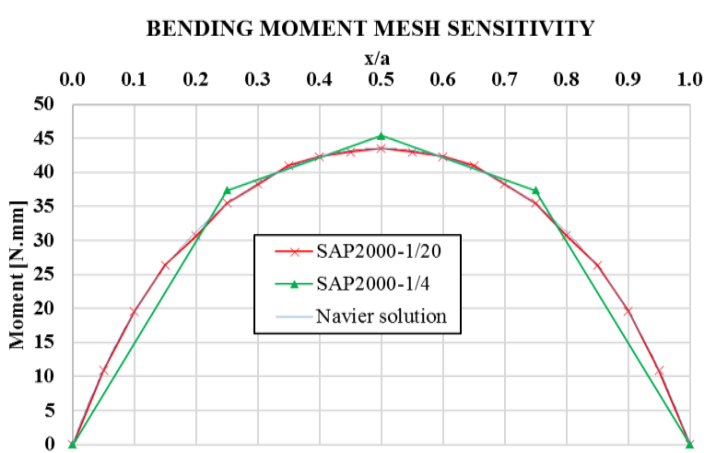

(b)

Fig. 3: 4-nodes quadrilateral shell-element responses mesh sensitivity in linear-elastic modeling.

\section{Results}

Based on the aforementioned-linear-elastic finite element model, a thorough investigation into various cases of boundary conditions and geometrical aspect ratios was conducted. Neglecting the effects of the time dimension and linearizing the material dimension, the resulting boundary value problem occurs in the 4D-BVP space. The seventh lemma (hypothesis) of the hydrostatic theory states that "in plates bending, for every boundary condition there exist an aspect ratio that renders the maximum response a hydrostatic point-moment-tensor, having zero radius; i.e. a zero deviatoric moment tensor. At such point, the principal moment's curves intersect in the 4D-BVP system". After conducting the FEA as per Table 1 for the case of all-sides simply supported, a normalization process took place in order to provide a loading-independent coefficient that can serve along with the superposition principle in plate analysis under 
any loading conditions and any plate dimensions. Based on that, the moment in the short and long directions can be found from Equation 9 and 10, respectively:

$$
M_{x}=C_{a} \cdot a^{2} \cdot p \quad M_{y}=C_{b} \cdot a^{2} \cdot p
$$

was adopted for the moment normalization in both directions. This was intended to preserve the directional influence of the dimensions and to isolate the hydrostatic phenomenon. Tables 2-5 list the results of the FEA of linear-elastic plates for various boundary conditions' cases. The results summarize the normalized moment coefficients for 11 plate thicknesses with a mesh density equal to the shorter span divided by 20 , which was found to be the optimum for plates analysis in linearelastic problem. The values in Tables 2 - 5 agree to some extent with those proposed by ACI-318 Code [27] for companion cases.

Table 2: Normalized negative and positive moment coefficients: FEA results of linear elastic plates for Cases 2 and 3.

\begin{tabular}{|l|c|c|c|c|c|c|c|c|}
\hline \multirow{2}{*}{$\begin{array}{c}\text { Aspect Ratio } \\
\text { Short }(a)\end{array}$} & \multicolumn{4}{|c|}{ Case 2: All Sides Clamped } & \multicolumn{4}{c|}{ Case 3: Short Sides Clamped } \\
\cline { 2 - 9 } Long $(b)$ & Negative Moment & \multicolumn{2}{|c|}{ Positive Moment } & \multicolumn{2}{c|}{ Negative Moment } & \multicolumn{2}{c|}{ Positive Moment } \\
\cline { 2 - 9 } & $\mathrm{C}_{\mathrm{a}}$ & $\mathrm{C}_{\mathrm{b}}$ & $\mathrm{C}_{\mathrm{a}}$ & $\mathrm{C}_{\mathrm{b}}$ & $\mathrm{C}_{\mathrm{a}}$ & $\mathrm{C}_{\mathrm{b}}$ & $\mathrm{C}_{\mathrm{a}}$ & $\mathrm{C}_{\mathrm{b}}$ \\
\hline 1.00 & 0.051 & 0.051 & 0.021 & 0.021 & 0.000 & 0.070 & 0.021 & 0.032 \\
\hline 0.95 & 0.055 & 0.053 & 0.023 & 0.021 & 0.000 & 0.074 & 0.024 & 0.033 \\
\hline 0.90 & 0.058 & 0.054 & 0.025 & 0.021 & 0.000 & 0.079 & 0.028 & 0.035 \\
\hline 0.85 & 0.064 & 0.055 & 0.028 & 0.020 & 0.000 & 0.087 & 0.034 & 0.037 \\
\hline 0.80 & 0.066 & 0.056 & 0.030 & 0.020 & 0.000 & 0.090 & 0.038 & 0.038 \\
\hline 0.75 & 0.033 & 0.056 & 0.033 & 0.018 & 0.000 & 0.097 & 0.045 & 0.039 \\
\hline 0.70 & 0.074 & 0.057 & 0.035 & 0.017 & 0.000 & 0.102 & 0.051 & 0.040 \\
\hline 0.65 & 0.077 & 0.057 & 0.037 & 0.016 & 0.000 & 0.107 & 0.058 & 0.040 \\
\hline 0.60 & 0.079 & 0.057 & 0.038 & 0.015 & 0.000 & 0.110 & 0.065 & 0.040 \\
\hline 0.55 & 0.081 & 0.057 & 0.040 & 0.015 & 0.000 & 0.115 & 0.074 & 0.040 \\
\hline 0.50 & 0.083 & 0.057 & 0.041 & 0.015 & 0.000 & 0.119 & 0.084 & 0.038 \\
\hline
\end{tabular}

Table 3: Normalized negative and positive moment coefficients: FEA results of linear elastic plates for Cases 4 and 5.

\begin{tabular}{|l|l|l|l|l|l|l|l|l|}
\hline \multirow{2}{*}{$\begin{array}{c}\text { Aspect Ratio } \\
\text { Short }(a)\end{array}$} & \multicolumn{3}{|c|}{ Case 4: Two Adjacent Sides Clamped } & \multicolumn{4}{c|}{ Case 5: Long Sides Clamped } \\
\cline { 2 - 9 } Long $(b)$ & Negative Moment & \multicolumn{2}{|c|}{ Positive Moment } & \multicolumn{2}{c|}{ Negative Moment } & \multicolumn{2}{c|}{ Positive Moment } \\
\cline { 2 - 9 } & $\mathrm{C}_{\mathrm{a}}$ & $\mathrm{C}_{\mathrm{b}}$ & $\mathrm{C}_{\mathrm{a}}$ & $\mathrm{C}_{\mathrm{b}}$ & $\mathrm{C}_{\mathrm{a}}$ & $\mathrm{C}_{\mathrm{b}}$ & $\mathrm{C}_{\mathrm{a}}$ & $\mathrm{C}_{\mathrm{b}}$ \\
\hline 1.00 & 0.069 & 0.069 & 0.030 & 0.030 & 0.070 & 0.000 & 0.032 & 0.021 \\
\hline 0.95 & 0.074 & 0.071 & 0.033 & 0.030 & 0.072 & 0.000 & 0.033 & 0.020 \\
\hline 0.90 & 0.078 & 0.073 & 0.035 & 0.030 & 0.074 & 0.000 & 0.034 & 0.020 \\
\hline 0.85 & 0.086 & 0.075 & 0.041 & 0.030 & 0.077 & 0.000 & 0.036 & 0.019 \\
\hline 0.80 & 0.090 & 0.077 & 0.043 & 0.029 & 0.078 & 0.000 & 0.037 & 0.018 \\
\hline 0.75 & 0.096 & 0.078 & 0.048 & 0.028 & 0.080 & 0.000 & 0.039 & 0.018 \\
\hline 0.70 & 0.102 & 0.079 & 0.051 & 0.027 & 0.081 & 0.000 & 0.040 & 0.018 \\
\hline 0.65 & 0.106 & 0.080 & 0.055 & 0.026 & 0.083 & 0.000 & 0.040 & 0.017 \\
\hline 0.60 & 0.110 & 0.080 & 0.057 & 0.025 & 0.083 & 0.000 & 0.041 & 0.017 \\
\hline 0.55 & 0.114 & 0.081 & 0.060 & 0.025 & 0.084 & 0.000 & 0.042 & 0.017 \\
\hline 0.50 & 0.118 & 0.081 & 0.064 & 0.024 & 0.084 & 0.000 & 0.042 & 0.017 \\
\hline
\end{tabular}


Table 4: Normalized negative and positive moment coefficients: FEA results of linear elastic plates for Cases 6 and 7.

\begin{tabular}{|l|c|c|c|c|c|c|c|c|}
\hline \multirow{2}{*}{$\begin{array}{c}\text { Aspect Ratio } \\
\text { Short }(a)\end{array}$} & \multicolumn{3}{|c|}{ Case 6: One Long Side Clamped } & \multicolumn{3}{c|}{ Case 7: One Short Side Clamped } \\
\cline { 2 - 9 } Long $(b)$ & Negative Moment & \multicolumn{2}{c|}{ Positive Moment } & \multicolumn{2}{c|}{ Negative Moment } & \multicolumn{2}{c|}{ Positive Moment } \\
\cline { 2 - 9 } & $\mathrm{C}_{\mathrm{a}}$ & $\mathrm{C}_{\mathrm{b}}$ & $\mathrm{C}_{\mathrm{a}}$ & $\mathrm{C}_{\mathrm{b}}$ & $\mathrm{C}_{\mathrm{a}}$ & $\mathrm{C}_{\mathrm{b}}$ & $\mathrm{C}_{\mathrm{a}}$ & $\mathrm{C}_{\mathrm{b}}$ \\
\hline 1.00 & 0.083 & 0.000 & 0.039 & 0.031 & 0.000 & 0.083 & 0.031 & 0.039 \\
\hline 0.95 & 0.088 & 0.000 & 0.041 & 0.030 & 0.000 & 0.088 & 0.035 & 0.040 \\
\hline 0.90 & 0.091 & 0.000 & 0.044 & 0.030 & 0.000 & 0.092 & 0.038 & 0.040 \\
\hline 0.85 & 0.098 & 0.000 & 0.048 & 0.033 & 0.000 & 0.098 & 0.046 & 0.042 \\
\hline 0.80 & 0.100 & 0.000 & 0.050 & 0.028 & 0.000 & 0.101 & 0.050 & 0.042 \\
\hline 0.75 & 0.105 & 0.000 & 0.053 & 0.027 & 0.000 & 0.106 & 0.057 & 0.042 \\
\hline 0.70 & 0.109 & 0.000 & 0.056 & 0.025 & 0.000 & 0.110 & 0.063 & 0.042 \\
\hline 0.65 & 0.113 & 0.000 & 0.059 & 0.025 & 0.000 & 0.113 & 0.070 & 0.042 \\
\hline 0.60 & 0.115 & 0.000 & 0.061 & 0.025 & 0.000 & 0.116 & 0.075 & 0.041 \\
\hline 0.55 & 0.118 & 0.000 & 0.064 & 0.024 & 0.000 & 0.119 & 0.084 & 0.039 \\
\hline 0.50 & 0.121 & 0.000 & 0.066 & 0.024 & 0.000 & 0.121 & 0.093 & 0.038 \\
\hline
\end{tabular}

Table 5: Normalized negative and positive moment coefficients: FEA results of linear elastic plates for Cases 8 and 9.

\begin{tabular}{|c|c|c|c|c|c|c|c|c|}
\hline \multirow{3}{*}{$\begin{array}{l}\text { Aspect Ratio } \\
\frac{\text { Short }(a)}{\operatorname{Long}(b)}\end{array}$} & \multicolumn{4}{|c|}{ Case 6: One Long Side Clamped } & \multicolumn{4}{|c|}{ Case 7: One Short Side Clamped } \\
\hline & \multicolumn{2}{|c|}{ Negative Moment } & \multicolumn{2}{|c|}{ Positive Moment } & \multicolumn{2}{|c|}{ Negative Moment } & \multicolumn{2}{|c|}{ Positive Moment } \\
\hline & $\mathrm{C}_{\mathrm{a}}$ & $\mathrm{C}_{\mathrm{b}}$ & $\mathrm{C}_{\mathrm{a}}$ & $\mathrm{C}_{\mathrm{b}}$ & $\mathrm{C}_{\mathrm{a}}$ & $\mathrm{C}_{\mathrm{b}}$ & $\mathrm{C}_{\mathrm{a}}$ & $\mathrm{C}_{\mathrm{b}}$ \\
\hline 1.00 & 0.055 & 0.061 & 0.022 & 0.027 & 0.061 & 0.055 & 0.027 & 0.022 \\
\hline 0.95 & 0.059 & 0.064 & 0.025 & 0.027 & 0.064 & 0.055 & 0.028 & 0.022 \\
\hline 0.90 & 0.064 & 0.066 & 0.028 & 0.028 & 0.068 & 0.056 & 0.030 & 0.021 \\
\hline 0.85 & 0.073 & 0.070 & 0.033 & 0.028 & 0.071 & 0.057 & 0.033 & 0.020 \\
\hline 0.80 & 0.077 & 0.073 & 0.035 & 0.028 & 0.073 & 0.057 & 0.034 & 0.019 \\
\hline 0.75 & 0.085 & 0.075 & 0.040 & 0.028 & 0.076 & 0.057 & 0.036 & 0.018 \\
\hline 0.70 & 0.091 & 0.077 & 0.045 & 0.027 & 0.079 & 0.057 & 0.038 & 0.018 \\
\hline 0.65 & 0.097 & 0.078 & 0.049 & 0.026 & 0.080 & 0.057 & 0.039 & 0.018 \\
\hline 0.60 & 0.103 & 0.079 & 0.052 & 0.025 & 0.081 & 0.057 & 0.040 & 0.018 \\
\hline 0.55 & 0.108 & 0.080 & 0.057 & 0.023 & 0.083 & 0.057 & 0.041 & 0.017 \\
\hline 0.50 & 0.115 & 0.081 & 0.061 & 0.022 & 0.083 & 0.057 & 0.042 & 0.017 \\
\hline
\end{tabular}

\section{Hydrostatic Parameters Estimation and Behaviour}

Based on the FEA, it was possible to obtain the hydrostatic moment parameters or the continuum moment tensor components. The following relations exist between the principal moments resulting in the hydrostatic parameters:

$$
H M_{c}=\frac{M_{1}+M_{2}}{2} \quad H M_{r}=\frac{M_{1}-M_{2}}{2}
$$

Applying the equations to the nine-cases results in a graphical illustration of the concept behind the seventh lemma of the hydrostatic theory (Figs. 4 and 5). Firstly, the principal extreme mid-span moments are introduced graphically based on the results obtained from the FEA (Tables 1 - 5). Selection of the extreme positive point moment serves the purpose of facilitating the introduction of material nonlinearity. This is more appropriate than the common practice in the factorized analysis of both negative and positive moments based on percentile ratios [28, 29].

The conceptual depiction of the growth behavior of the hydrostatic parameters in the plate is introduced as the plate geometrical aspect diverges toward the state of the pure beam behavior. This growth would always initiate from the hydrostatic point phenomenon, at which the radius of the Mohr circle is a point with a zero radius, or at which a pure 
Gaussian spherical curvature occurs with the absence of any twisting deviatoric curvature. This point can be established as the reference point for such growth models and for the establishment of the two-way behavior. This in fact dissipates the misunderstanding of the two-way pure behavior that describes it with the square geometry. Fig. 4. shows the principal moments and Mohr circle growth at the extreme positive section. Fig. 5. shows the hydrostatic and deviatoric moment components growth curves for aspect ratios of 0.5-1.0. Curves for all other cases can be found in [20].

For example, for Case 1 "All-Sides Simply Supported Plate", Fig. 4 shows that the two-way action occurs precisely as the geometrical aspect ratio of $a / b=1$. Following which and through fixing $a$ and extending $b$, the extreme point Mohr circle develops from the hydrostatic point phenomenon in terms of both a growth in the hydrostatic component and a more radical growth in the deviatoric component. The largest principal moment $\left(M_{a}\right)$ develops a higher magnitude as the aspect ratio increases. This is true until such moment value would converge though approaching the infinite aspect ratio (the reciprocal of zero) to the pure simply supported beam response. At such point the maximum principal moment coefficient reaches a value of $1 / 8$ based on mechanics' formulations [30]. In contrast, the minimum principal moment approaches zero at the infinite aspect ratio. Concurrently, this behaviour is accompanied on one hand with the increase in the hydrostatic moment component from the hydrostatic phenomenon least curvature state to the high curvature state of the pure beam behaviour at the infinity. On the other hand, the deviatoric component growth increases radically from zero to approach the hydrostatic component at the infinity aspect ratio for a pure beam behaviour. These conditions can be represented using mathematical expressions. If the ratio $(a / b)$ represents the ratio of short to long dimensions; for the case of all-sides simply supported plate, the mathematical functions of the hydrostatic and deviatoric components of the moment state can be summarized with the following expressions defining its range and domain:

$$
\begin{gathered}
H M_{c}(a / b): \begin{cases}(0,1] \rightarrow[0.044,0.0625) ; \forall(a / b) \leq 1 \text { and } a / b \geqq 0 \\
{[1, \infty) \rightarrow[0.044,0.0625) ; \forall(a / b) \geq 1 \text { and } a / b \nsupseteq \infty}\end{cases} \\
H M_{r}(a / b): \begin{cases}(0,1] \rightarrow[0,0.0625) ; \forall(a / b) \leq 1 \text { and } a / b \geqq 0 \\
{[1, \infty) \rightarrow[0,0.0625) ; \forall(a / b) \geq 1 \text { and } a / b \nsupseteq \infty}\end{cases}
\end{gathered}
$$

If the ratio $(a / b)$ represents the longer to shorter ratio, a symmetry in the response is encountered due to identical boundary conditions. Similar formulation and set of equations are developed in details for all cases [20].

\section{Conclusion}

A true understanding of the two-way plate action was achieved; in which the hydrostatic point phenomenon was established as the reference point for identifying plates with actual two-way action. The innovative selection of the extreme positive point moment serves the purpose of facilitating the introduction of material nonlinearity into the design. This is more appropriate than the common practice in the factorized analysis of both negative and positive moments based on percentile ratios. The use of the shorter dimension for the moment normalization in both directions preserves the directional influence and isolates clearly the hydrostatic phenomenon. On the basis of extreme point with the hydrostatic phenomenon occurrence at a plate, it was identified that such occurrence can be established as the growth reference for other cases. Thus, the plate response based on geometrical and boundaries differences, can be modeled with growth models for both the hydrostatic and deviatoric moment tensors. For any boundary conditions, through starting at a hydrostatic phenomenon occurrence and via fixing dimension (a) and extending the perpendicular dimension (b), the extreme point Mohr circle develops from the hydrostatic point phenomenon in terms of both a growth in the hydrostatic component and a more radical growth in the deviatoric component. The largest principal moment $\left(\mathrm{M}_{\mathrm{a}}\right)$ develops a higher magnitude as the aspect ratio increases. For identical boundary conditions in both directions, a symmetry in the response is encountered. The presence of non-identical boundary conditions in the plate on two perpendicular directions would result in a deviation of the two-way action. 

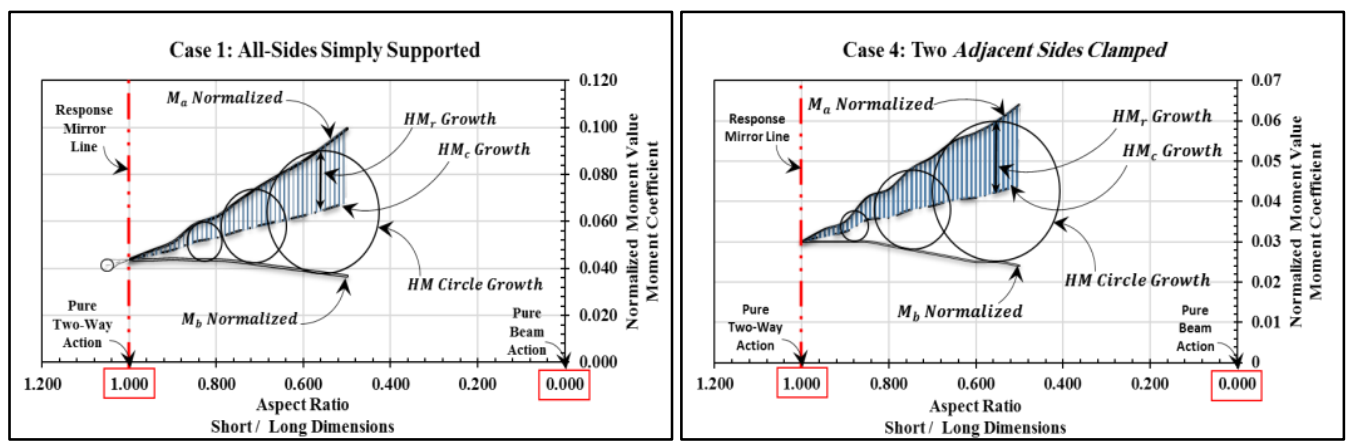

Fig. 4: Principal moments and Mohr circle growth behavior at the extreme positive section.
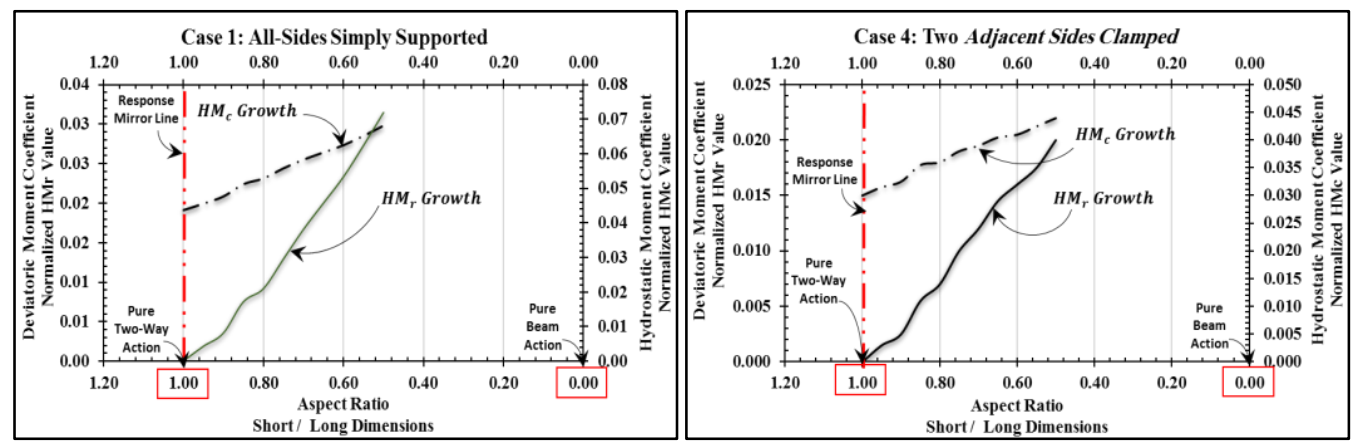

Fig. 5: The hydrostatic and deviatoric moment components growth curves for 0.5-1 aspect ratios.

\section{Acknowledgements}

The authors acknowledge the support provided by Jordan University of Science and Technology (JUST).

\section{References}

[1] K. E. Kurrer, The History of the Theory of Structures. Germany: Wiley-VCH Verlag GmbH \& Co. KGaA, 2008.

[2] M. Kamara, M. Mahamid, and L. Novak. Historical Perspective on the Evolution of Two-Way Slab Design. Special Publication, 2012.

[3] R. J. W. Milne, Structural Engineering: History and Development. Taylor \& Francis, 1997.

[4] G. Galilei, Dialogues Concerning Two New Sciences 1638. South Australia: Macmillan, 1914.

[5] L. Euler, "Recherches sur la courbure des surfaces," Research into the curvature of surfaces, vol. 16, no. 1., 1760.

[6] L. Euler, "De motu vibratorio tympanorum (On the motion of vibrations in drums)," Novi Comment, Acad. Sci. Petropolitanae, vol. 10, no. 1, pp. 243-260, 1766.

[7] L. Euler, "Tentamen de sono campanarum (An effort on the sound of bells)," Novi Comment, Acad. Sci. Petropolitanae, vol. 10, no. 1: pp. 261-281, 1966.

[8] D. O'. Mathuna. Jacques II Bernoulli and the Problem of the Vibrating Plate. DIAS-STP 1994.

[9] R. Szilard, Theories and Applications of Plate Analysis: Classical, Numerical and Engineering Methods. Hoboken, New Jersey: John Wiley \& Sons, Inc., 2004.

[10] E. Ventsel, T. Krauthammer, and E. Carrera, "Thin Plates and Shells: Theory, Analysis, and Applications," Applied Mechanics Reviews, vol. 55, no. 4, 2001.

[11] A. C. Ugural. Stresses in Beams, Plates, and Shells. 2010.

[12] S. Germain, Recherches sur la théorie des surfaces élastiques. Paris: Mme. Ve. Courcier, 1821.

[13] S. Germain, Remarques sur la nature, les bornes et l'étendue de la question des surfaces élastiques et équation générale de ces surfaces. impr. de Huzard-Courcier, paris, 1826.

[14] S. D. Poisson, Memoire sur l'equilibre et le mouvement des corps elastique. in Mémoires de 1'Académie des sciences de 1’Institut de France, Académie des sciences, Ed. Paris: Gauthier-Villars, pp. 357-580, 1829. 
[15] G. Kirchhoff, "Über das Gleichgewicht und die Bewegung einer elastischen Scheibe," J. fur die Reine und Angew. Math.; vol. 18, no. 40, pp. 51-88, 1850.

[16] G. Kirchhoff, Vorlesungen über mechanik (Lectures on Mechanics), 4th ed. Leipzig: Leipzig, B. G. Teubner, 1897.

[17] S. Timoshenko and S. Woinowsky-Krieger, Theory of plates and shells. 2nd ed. New York: McGraw-Hill, 1959.

[18] A. Einstein and H. Minkowski, The Foundation of the Generalised Theory of Relativity. in the principle of relativity; original papers, The University of Calcutta, pp. 89-163, 1920.

[19] J. D. Norton, "General covariance and the foundations of general relativity: eight decades of dispute," Reports Prog. Phys., vol. 56, no. 1, pp. 451-458, 1993.

[20] M. A. Hejazi, Innovative Approach for Analyzing Thin Thick Plates Considering Non-linearity and Plasticity with Damage for Various Boundary Conditions. Masters' Thesis, Jordan University of Science and Technology, 2018.

[21] CSI, CSI Analysis Reference Manual, Computers \& Structures Inc., USA, 2017.

[22] C. L. Navier, "Extrait des recherches sur la flexion des planes élastiques. Bull. des Sci. Société," Philomath, Paris, vol. 10, no. 1, pp. 92-102, 1823.

[23] C. L. Navier, Résumé des Leçons données à l'Ecole Royale des Ponts et Chaussées sur l'Application de la Mécanique à l'Etablissement des Constructions et des Machines. 1er partie: Leçons sur la résistance des materiaux et sur l'établissement des constructions en terre,. Paris: Firmin Didot père et fils, 1826.

[24] C. L. Navier, "Remarques sur l'article de M. Poisson, inséré dans le cahier d'août, Annales de chimie et de physique," Landmarks II, Sci. journals vol. 39, no. 1, pp. 145-151, 1828.

[25] M. Lévy, "Mémoire sur la théorie des plaques élastiques planes," J. Math. Pures Appl., vol. 3, no. 1, pp. 219-306, 1877.

[26] M. Lévy, "Sur l'équilibre élastique d'une plaque rectangulaire," Comptes rendus l'Académie des Sci. Paris, vol. 129, no. 1 , pp. 535-539, 1899.

[27] ACI Committee 318. Building Code Requirements for Structural Concrete. ACI 318-14. MI, 2014.

[28] J. O. Corley and W. G. Jirsa, "Equivalent Frame Analysis For Slab Design," ACI J., vol. 67, no. 11, pp. 875-884, 1970.

[29] F. Kerekes and H. B. Reid Jr., "Fifty Years of Development in Building Code Requirements for Reinforced Concrete," ACI J. Proc., vol. 50, no. 2, pp. 441-471, 1954.

[30] W. C. Young and G. Budynas, Roark's Formulas for Stress and Strain. 7th ed. McGraw-Hil, 2002. 